Revista aSEPHallus de Orientação Lacaniana

Núcleo Sephora de Pesquisa sobre o Moderno e o Contemporâneo

ISSN $1809-709 \mathrm{X}$

\title{
Ideologia, você quer uma pra viver?
}

\author{
Tania Coelho dos Santos \\ Pós-doutorado no Departamento de Psicanálise de Paris VIII (Paris, França) \\ Professor Associado, nível IV no Programa de Pós-graduação em Teoria Psicanalítica/ UFRJ \\ (Rio de Janeiro, Brasil) \\ Pesquisadora do CNPQ nível 1 C (Brasil) \\ Presidente do Instituto Sephora de Ensino e Pesquisa de Orientação Lacaniana / ISEPOL \\ (Rio de Janeiro, Brasil) \\ Psicanalista Membro da École de La Cause Freudienne, da Escola Brasileira de Psicanálise e \\ da Associação Mundial de Psicanálise \\ Membro da Associação Universitária de Pesquisa em Psicopatologia Fundamental (Brasil) \\ E-mail: taniacs@openlink.com.br
}

\begin{abstract}
Resumo
Educar é uma missão impossível ou é uma ideologia caduca? A psicanálise precisa da educação? Freud a considerava um processo de pós-educação (Nachlehren). Ele aspirava que seu método de investigação do funcionamento psíquico pudesse ter efeitos de retificação sobre a educação defeituosa, quando ela limitava demais a pulsão e dificultava a sublimação. A educação dos psicanalistas precisa da universidade? O projeto de uma sociedade igualitária se apoia na universalização do acesso a educação. Mas ele vacila. Qual é o real em jogo? Enquanto analista, penso que a ideologia igualitária é um grande equívoco. A educação não leva à sua realização, ao contrário, acentua as diferenças, pois aparelha os mais aptos a vencer. Vivemos num impasse aparentemente sem solução. Apostar na meritocracia e acentuar as diferenças ou fomentar a igualdade de todos com todos e o nivelamento por baixo?

Palavras-chave: psicanálise, educação, formação analítica.
\end{abstract}

\section{Voulez-vous une idéologie pour vivre?}

L'éducation est-elle une tâche impossible ou une idéologie caduque? La psychanalyse a-t-elle besoin de l'éducation? Freud la considérait comme un processus de post-education (Nachlehren). Il aspirait a voir sa methode d'investigation du fonctionnement psychique réussir a produire un effet rectificateur sur l'éducation défectueuse quand elle limitait trop la pulsion et difficultait la sublimation. L'université est-elle nécessaire pour faire l'éducation des psychanalystes? Le projet d'une société égalitaire repose sur l'acces universel a l'éducation. Mais ce projet vacille. Quel est l'enjeu du réel? En tant qu'analyste, je pense que l'idéologie égalitaire est une grande erreur. L'éducation ne mène pas a sa réalisation, au contraire, elle ne fait que souligner les differences puisqu'elle ne fait qu'équiper les plus doués. Nous vivons dans une impasse qui semble n'avoir aucune issue. Miser sur la méritocratie et exacerber les differences ou stimuler l'égalité de tous avec tous et le nivellement par le bas?

Mots-clés: psychanalyse, education, formation analytique.

\section{Do you want an ideology to live by?}

Is Educating an impossible task or is a deciduous ideology? Does psychoanalysis need education? Freud considered it a post-education process (Nachlehren). He aspired that his psychic functioning investigation method could have effects on the rectification of defective education, when it excessively limits drive and creates difficulties for sublimation. Does the education of psychoanalysts need the university? The project of an egalitarian society is based on universal access to education. Unfortunately it is faltering. What is the real at stake? As an analyst, I think the egalitarian ideology is a mistake. Education does not lead to its realization, in contrast, emphasizes the differences, because it equips the fittest to win. We live in a seemingly hopeless impasse. Betting on meritocracy and accentuating the differences or to promoting the equality of all and the lowering of the standards?

Keywords: psychoanalysis, education, analytical teaching. 


\title{
Ideologia, você quer uma pra viver? ${ }^{1}$
}

\author{
Tania Coelho dos Santos
}

\section{Educar, governar, psicanalisar....}

Educar é uma missão impossível ou é uma ideologia caduca? A psicanálise precisa da educação? Freud a considerava um processo de pós-educação (Nachlehren). Ele aspirava que seu método de investigação do funcionamento psíquico pudesse ter efeitos de retificação sobre a educação defeituosa, quando ela limitava demais a pulsão e dificultava a sublimação. A educação dos psicanalistas precisa da universidade?

O Núcleo Sephora está fazendo quinze anos. Mas não somos debutantes. Apostei na importância da pós-graduação para a formação dos analistas. Muitos analistas não pensam assim. Mestrados e doutorados são ferramentas para entrar no mercado de trabalho com mais competência e capacidade de inovação. Muitas teses, dissertações e monografias concluídas no Núcleo Sephora, embasam programas de psicanálise aplicada! Nisso, somos veteranos! Vamos pensando a modernidade e a contemporaneidade com Freud, com Lacan e mais recentemente com JacquesAlain Miller.

Neste IV Simpósio do ISEPOL, não estamos sozinhos. O Jorge Forbes, a Ana Lydia Santiago, a Leny Mrech, a Maria José Gontijo e a Nádia Laguardia trouxeram ao nosso baile de veteranos, um pouco da pesquisa e da ação que efetuam na USP, na UFMG e na EBP. Com a Rosinda Oliveira da UFRJ, encaramos um diálogo firme com a neuropsicologia e com a psicopedagogia.

\section{Medicalização do TDAH e políticas de inclusão}

A pratica da psicanálise aplicada em instituições escolares tem sido confrontada à uma tendência inquietante, por parte de professores e coordenadores, de procurarem diagnósticos neurológicos que justifiquem a medicalização de manifestações sintomáticas da infância. Os transtornos de comportamento tais como as atitudes desafiadoras para com as figuras de autoridade, hiperatividade, desatenção, desinteresse pelos conteúdos em sala de aula são encarados como sinais de um quadro neurológico cujo tratamento é a combinação de Ritalina com métodos de reeducação cognitiva e comportamental. Calar a criança, reeducá-la e à sua família, recusar a dimensão necessariamente equívoca do campo da fala e da linguagem e nada querer saber do gozo pulsional que habita os seres falantes, paradoxalmente, alimenta as políticas inclusivas. Crianças diagnosticadas como TDAH (Transtorno de déficit de atenção e hiperatividade), têm direito assegurado a serem tratadas como exceção no ambiente escolar. Configuram um dos muitos casos de direito à inclusão. Precisamos pensar sobre os efeitos colaterais, nesta época do direito ilimitado ao gozo, das políticas de inclusão. Tempo em que as individualidades e minorias tomam a forma de movimentos sociais que engrossam a reivindicação generalizada de ser tratado como exceção.

Cada vez menos é possível sustentar a fiç̧ão de uma ordem simbólica para todos. Vivemos numa pluralidade de ordens simbólicas localizadas e de Nomes-do-pai ou de objetos de gozo sob 
medida para cada uma delas. Que estratégia clínica adotaremos frente aos efeitos do progresso da ciência e do capitalismo de desvelamento e de nomeação do real sem lei? A ordem simbólica inspirada na imitação da natureza vem sendo destruída. A regulação dos usos do corpo e dos prazeres fundada nos ciclos da vida - nascimento, infância, adolescência, juventude, maturidade, envelhecimento e morte - cede seu lugar à demanda de uma infinidade de vidas infinitamente felizes. Quando nada mais é impossível, uma grande desordem pulsional e o apelo crescente à regulação por meio da medicação comparecem com assiduidade entre os novos costumes.

\section{A subjetividade contemporânea e seus analistas}

Em outro artigo recente (Coelho dos Santos, 2013) eu me perguntava: quais são as ficções que os sujeitos fabricam nos dias de hoje para defender-se do real traumático, do que não tem sentido, de tudo aquilo que é impossível evitar? As novas respostas ao real no século XXI dependem, talvez, da lógica homogeneizante (todo homem nasce livre e igual) que provoca o rebaixamento da lei simbólica à norma contratual. Paradoxalmente, o imperativo igualitário e suas práticas disciplinares e homogeneizantes convivem com os biopoderes que produzem como efeito indivíduos que reivindicam, politicamente, em nome do direito à vida, o "direito de serem tratados como exceção". Toda uma lógica social de gestão das populações e de controle do risco ergue-se a partir dessas injunções. A sociedade em que vivemos precisa saber quem são seus psicanalistas. A resposta da Associação Mundial de Psicanálise ao problema da regulamentação dessa prática na sociedade do controle e do risco é a de apostar nos poderes discriminadores do dispositivo do passe para distinguir quem são os analistas dispostos a fazer da exposição pública dos efeitos de sua análise pessoal uma ferramenta para causar o desejo pela psicanálise.

Convém lembrar que ao término de uma análise, a desmontagem da fantasia desvela o real sem lei da pulsão e permite nomear o resto incurável onde se aloja o gozo singular de cada um. Resta saber que aplicação política podemos fazer desta experiência no campo da saúde na educação. Durante muitos anos eu me dediquei a estudar os efeitos da difusão da psicanálise (Coelho dos Santos, 2001). Queria saber sobre os efeitos colaterais de uma prática de interpretação do inconsciente que terminava com a instalação de um novo discurso: o discurso analítico. Este discurso coloca o objeto $a$, objeto da pulsão, no lugar do agente. É uma tarefa árdua distingui-lo do discurso da sociedade de consumo, também ele orientado pelo objeto da pulsão e avesso à soberania dos ideais. Que ideologia fomentam estes discursos? Seria talvez a injunção: a cada um seu resto, seu objeto de gozo, sua maneira singular de viver? Viveremos numa sociedade de exceções? Será preciso um esforço a mais para incluir cada um ou não haverá mais onde incluir ninguém quando o tecido social, outrora constituído pela norma, pelo Nome-do-Pai, pelo supereu transindividual simplesmente desapareceu?

\section{O lugar certo onde colocar o desejo e o direito ao gozo}


No último simpósio do Isepol, contei aos meus ouvintes que, em outubro de 2012, durante a assembleia de membros da École de la Cause, Jacques-Alain Miller, com seu estilo provocador e polêmico, propôs que a escola discutisse a seguinte questão: ter um desejo é ter um direito? Ter um desejo é a mesma coisa que ter o direito de realizá-lo? Realizá-lo é a mesma coisa que alcançar a satisfação esperada? Esta questão orientou o III Simpósiodo Isepolque intitulei: "O lugar certo onde colocar o desejo do analista na era dos direitos". Retomo aqui algumas das colocações que pude fazer naquela ocasião, costurando assim o tema daquele encontro com o tema que vamos discutir hoje. Se como ensina Lacan em seu seminário sobre a ética da psicanálise, nada do que se busca é da ordem do que se encontra, é porque a única lei que determina o desejo é o vazio, sua causa. 0 real, deste ponto de vista, é o que retorna no mesmo lugar. 0 inconsciente é o retorno daquilo que nos causa, nos determina e se reapresenta sob novas roupagens metafóricas e metonímicas. Existiria, portanto, um "saber no real". Saber que reclama a interpretação, que o aborda de forma sempre assintótica, não podendo jamais reproduzi-lo, somente traduzi-lo.

O último ensino de Lacan, diferentemente, vem situar no coração da experiência analítica o encontro com um "real sem lei", que desarranja nossa convicção de que o inconsciente se reduza ao retorno do recalcado. Miller (2012), diz que é preciso renovar a prática da psicanálise no mundo reestruturado pela aliança de dois discursos, o do capitalismo e o da ciência. A dominação combinada destes dois discursos rompeu com os fundamentos mais profundos da tradição. $O$ desarranjo da ordem simbólica cuja pedra angular é o Nome-do-Pai revelou a "inexistência da relação sexual" na espécie dos seres vivos que falam. Esta função chave - agora reduzida a apenas um sintoma entre outros - servia para suplementar este furo. O rebaixamento da função do Nome-do-Pai à categoria de um sintoma entre outros, abala os fundamentos da diferença entre a neurose e a psicose, homem e mulher, adulto e criança. Sem a função chave do Nome-do-Pai, não existe mais nenhuma garantia da ordem simbólica, não há mais Outro do Outro. A grande desordem no real é a consequência de que a natureza não é mais o nome do real. A ordem humana, a família como formação social não se inspira mais na natureza.

Somente alguns meses depois percebi que essa pergunta formulada por Miller tinha sua fonte nas proposições do capítulo final do Seminário VI: o desejo e sua interpretação, de Lacan (1958-1959), que foi lançado pouco depois em Paris. Ela foi suscitada com o objetivo de motivar a organização de um evento ${ }^{2}$ sobre o tema dos desejos e dos direitos. De acordo com Lacan (19581959), a cultura perpassa a sociedade, desagregando-a. Existe entre a sociedade e a cultura uma relação entrópica, isto é, disjuntiva. A cultura deixa aberto o mesmo vazio, no interior do qual situamos a função do desejo. Neste sentido, a perversão é um protesto contra a identificação ao padrão de comportamento que instaura, regula e ordena as normas de estabilização social das diferentes funções. Instala-se uma dinâmica circular entre o conformismo às normas sociais e a atividade cultural. Esta última se aproxima da perversão, pois eleva à dimensão do desejo a relação do sujeito ao ser vazio de sentido. Aqui se inscreve a sublimação que é a forma que toma o desejo esvaziado de sua relação a um objeto determinado. 0 desejo fica assim reduzido apenas à pulsão 
sexual, ao puro jogo de significantes. Na sublimação, que é um dos destinos da pulsão, o desejo equivale à letra e resiste - tal como a perversão - a toda forma de normalização, padronização, homogeneização.

É preciso indagar qual é a relação entre a era dos direitos e o progresso da ciência. À medida que a ciência assegura a transposição de antigos limites, cresce a potência da demanda de usufruir de satisfações inéditas. O campo do direito, desde a Declaração Universal dos Direitos Humanos (1948), não cessa de promover o direito ao desejo de cada um, muitas vezes em detrimento do direito de todos. A velha máxima - a liberdade de cada um termina onde começa a do outro - está francamente caduca. $O$ direito de uns, se paga com o não direito de outros. Ter um desejo é ter um direito? Nessas situações trata-se ainda do direito à perversão própria ao desejo, em detrimento do conformismo às normas que sustentam os laços sociais?

\section{Do Nome-do-Pai à ordem de ferro ou do supereu ao supersocial}

No artigo recente, já mencionado acima, (Coelho dos Santos, 2013) destaco que não introduzo estas anotações como uma socióloga faria, mas como alguém que aprendeu a abordar a subjetividade de sua época a partir dos impasses transferenciais no dispositivo analítico. É com esta métrica que nós, analistas, medimos a distância e a proximidade entre as neuroses e psicoses freudianas clássicas e as neuroses e psicoses contemporâneas. Recordo aqui mais uma vez que o Nome-do-Pai é a medida comum, a lei simbólica com função de interditar o gozo e permitir o desejo. Como é do conhecimento de todos os analistas lacanianos, a distinção entre a neurose e a psicose clássica baseia-se na presença ou na ausência da simbolização do Nome-do-Pai. Na psicose, o Nomedo-Pai foracluído do simbólico não funciona a serviço da interdição do gozo, logo, não instala a lei do desejo e da diferença sexual. A novidade que nos interessa destacar mais uma vez nas páginas desse artigo é que de acordo com Lacan (1973-1974, aula de 9/3/1974), no discurso da civilização contemporânea o Nome-do-Pai foracluído do simbólico retorna no real das normas sociais. MarieHélène Brousse (2009) interpreta essa intuição lacaniana como a substituição desse operador simbólico pela cifra, pela média, pela curva de Gauss, cujo centro é a ordem social. O politicamente correto é o consenso. A normalidade é a mediana. O sentido sexual se transformou em sentido social, comum, ordinário. Lacan qualifica esta nova ordem social como "ordem de ferro" (Lacan, 1973-1974, aula de 19/3/1974), pois ela é mais feroz do que a interdição pelo Nome-do-Pai que dá lugar ao desejo. O correlato da "ordem de ferro" é o imperativo do gozo. A psicose dos dias de hoje é ordinária, no sentido de banal, e é correlativa da "ordem de ferro". Segundo Éric Laurent, a psicose ordinária não responde aos significantes mestres tradicionais, manifestando o fim do poder de normalização (no sentido de sublimação) do Nome-do-Pai enquanto único significante da lei simbólica. Na psicose ordinária, diferentemente da psicose clássica, o sujeito não se consagra a encarnar o lugar da exceção que falta à ordem simbólica. A consequência prática é que o supereu, herdeiro das identificações secundárias ou pós-edipianas, foi substituído pelo supersocial. Estamos 
vivendo a época do politicamente correto, dos contratos intersubjetivos que abolem o valor dos significantes, mestres das tradicões.

\section{A clínica da subjetividade normalizada por meio consenso de pares}

Apostei boa parte da minha vida na ideologia da mudança social pela educação. Essencialmente, educar é um ato que se funda na dissimetria entre as gerações. Trata-se de transmitir um saber que se recebeu dos seus pais e mestres. $O$ mito da igualdade de oportunidades depende do sucesso do processo educativo. Confesso que tenho me sentido um pouco como o Cazuza: "Os meus sonhos foram vendidos, tão barato..., que eu nem acredito!" O que é uma ideologia? É essa espécie de estrutura que Lacan nos ensinou a chamar de discurso, um efeito puro e simples de linguagem que engendra um laço social. Acreditar que o investimento em educação, reduz a desigualdade social e alavanca trajetórias ascendentes bem sucedidas, é uma ideologia. Mas, o sucesso não garante que haverá inclusão. Neste ponto, a ideologia encontra o real. Pois, de sua origem, um sujeito leva hábitos muito arraigados que a ascensão social não apaga.

Será que é por isso que vivemos num país que não acredita em investir no caminho árduo e longo da aquisição do saber? Para combater a desigualdade social a política dominante escolhe a inclusão pela distribuição de renda e nivelamento dos hábitos de consumo. Afinal, quando quase todo mundo tem celular, micro-ondas, geladeira, parecemos mais iguais, mais livres, mais democráticos. Estudar pra quê? Hoje, é mais importante fazer parte de um grupo com interesses em comum, lutar pelos seus direitos, reivindicar. Os movimentos sociais são o caminho alternativo escolhido pelos desencantados com a educação. Como Cazuza, eu me pergunto: "Meus heróis morreram de overdose? Meus inimigos estão no poder? Ideologia, eu quero uma pra viver?".

Passo a contar algumas estórias que recolhi durante entrevistas relacionadas com a supervisão de serviços de orientação educacional. Com 15 anos, João esbraveja: "Eu detesto ir pra escola. Não sei por que me obrigam a estudar. Meu pai não fez faculdade nenhuma e ficou rico. E os professores? Estudaram tanto e ganham pouco, trabalham muito e ninguém quer ser igual a eles. Eu quero jogar futebol. Quero ficar rico, rápido. Estou perdendo tempo na escola. Quero entrar para o Barcelona, treinar para ser um craque".

A perda do valor da ideologia da educação manifesta-se na hesitação, na preguiça e até na má vontade de pais e professores em transmitir seus princípios às novas gerações. Perdi a conta do numero de vezes que escutei de pais e mães: Não sei o que é melhor pro meu filho. As coisas mudaram... Eles sabem mais que a gente viver nesse mundo. Por isso, nas escolas de hoje, em lugar de princípios universais tais como: "o direito de um termina onde começa o do outro", novas práticas encorajam as crianças a fazerem "combinados". Atrás da porta de cada sala de aula, algumas regras escritas, sintetizam o frágil consenso social arbitrado entre os alunos. Outras regras de convivência social desapareceram do mapa. Não é preciso mais fazer silêncio enquanto o professor dá sua aula. As novas gerações não conhecem o ditado "quando um burro fala o outro abaixa a orelha". 
Alice confessa: "Não consigo prestar atenção. É muito barulho, todo mundo fala ao mesmo tempo".

- E o que fazem os professores? Pergunto, me fazendo de ingênua.

- "Reclamam, ameaçam anotar na agenda, vão se queixar ao coordenador, chamam o SOE, mas não adianta nada".

A impotência dos professores diante da balbúrdia que se instala nas salas de aula demonstra quem é que manda no espaço escolar. Aos alunos, são atribuídos poderes ilimitados e todos os adultos fazem de conta que cabe aos estudantes responsabilizarem-se pelo desejo de aprender. 0 nome disso é autonomia. As crianças e adolescentes devem ter autonomia, devem querer aprender. O desejo de saber não deve nada ao desejo do Outro, do adulto, dos pais ou dos mestres. A ideologia dominante nos dias de hoje, oculta, mascara, mente sobre a obrigação constitucional dos adultos de educarem as novas gerações. Será que o discurso analítico contribuiu para este estado de coisas? Será que difundimos a crença de é apenas o desejo de cada um que está em jogo no desejo de aprender? Será que os psicanalistas colaboraram para cultivar este maciço desconhecimento do papel desempenhado pelo desejo do Outro no campo da educação? Podemos apontar aí a conjunção entre o discurso analítico e o discurso da civilização? Ambos obscurecem o lugar de agente significante mestre e elevam ao Zenith, conduzem ao lugar de agente o objeto $a$ ?

O efeito desta conjunção sobre o supereu é o crescimento das patologias do ato: impulsividade, compulsão e excesso. É comum ouvir de crianças e adolescentes: "eu não me controlo..." ou ainda, "é mais forte do que eu...". Condição psíquica que torna impotentes todas as formas de punição. A instituição educativa assemelha-se cada vez mais a uma instituição psicoterapêutica.

Não é mais verdade, por exemplo, que a sua "liberdade termina onde começa a do outro". Os corpos falantes indisciplinados quase não se distinguem uns dos outros, na massa confusa da tagarelice e da agitação. Seus corações e mentes são coletivos. A individualidade de cada um não é um valor. O consenso entre pares prevalece, impondo o desejo de consumir tudo que está na onda, que está bombando. Você tem que ser popular. Ter Iphone5, tablet, mini-mc, frequentar e conhecer outros filhos de gente importante. Tem razão quem grita mais alto. A regra é simples, todo mundo faz, o que todo mundo faz. Quem não está dentro é nerd. Uma sala de aula não funciona como uma turma sob a regência do professor. São tribos de índios barulhentos e agitados sem nenhum cacique!

O exercício do senso crítico, por exemplo, é coisa de gente mal-humorada, autoritária e controladora. Você tem que saber ser persuasivo, agradar, exibir-se ser popular. É o reino das personalidades narcísicas!

Confusos e impotentes, os professores clamam pela intervenção urgente dos neuropsiquiatras. $O$ sonho coletivo dos educadores pode ser resumir conforme se segue: a vigilância sanitária podia botar Ritalina na água da CEDAE! Colocar flúor na água, para combater a cárie, não deu tão certo? Será que não resolveria o problema epidemiológico do TDAH? Transtorno de déficit de atenção e hiperatividade, esse é o nome do novo sintoma que acomete a população escolar. É 
um sintoma que afeta a posição do sujeito, quando ele se comporta como um objeto no laço social. Falam dele, é repreendido, anotam queixas em sua caderneta, levam ao coordenador, chamam seus pais e, no final, quando todos os adultos estão exaustos, o Serviço de Orientação Educacional os encaminha para o psicólogo ou para o neurologista. A quantidade de crianças controladas com medicação é significativa e não para de crescer.

Um adolescente de 12 anos me diz: "Não faço ideia de porque meu pai fala cinco vezes a mesma coisa e eu digo que depois eu faço. Aí ele grita, fica descontrolado, meu irmão chora, fico de castigo. Quando a minha mãe fala comigo, digo sempre não. Ela se descontrola, me ameaça, me põe de castigo. Mas nada adianta. Eu tenho medo de dormir sozinho. Então eu peço a ela para dormir na cama dela. Os professores gostam de mim mas não me suportam, eu questiono tudo, não aceito nada". Já conheço os passos dessa estrada. O próximo passo é a ritalina! É o supereu farmacológico.

O supereu, aquela instância psíquica que é o produto das identificações com os pais, professores e autoridades, deu lugar a uma outra coisa muito diferente. Lacan em 1974, já antecipava o surgimento do supersocial! O supersocial é da época dos comitês de ética, que estabelecem as normas de comportamento. São as tribos de pares que formulam seus manuais de etiqueta, seus combinados. Esta normatividade imperativa dos grupos sociais combate freneticamente a responsabilidade subjetiva. Na era da defesa das normas de cada tribo, toda a responsabilidade é pura e simplesmente social. A próxima geração de psicanalistas será chamada de socioanalistas? Ou serão, talvez, sóciossintetizadores? Não vão mais ensinar que o aparelho psíquico é constituído de um isso, de um eu e de um supereu. Não vão ensinar que estas dimensões intrapsíquicas experimentam um conflito entre elas, pois representam interesses distintos: a pulsão, a realidade externa e a consciência moral. Vão ensinar que existem as necessidades ou os direitos, a tribo de pares e os comitês de ética. Eles vão cantar com o profeta Cazuza, "eu vou pagar a conta do analista, pra nunca mais ter que saber quem eu sou!".

"Você acha certo?", me pergunta Lucas. "A professora mandou fazer um trabalho em grupo. Cada um tinha a sua parte. Eu, o José e o Patrick fizemos a nossa parte. O Felipe e o Pedro não entregaram. Ela tirou quatro pontos de todo mundo. Ficamos com nota seis". Lucas tem 14 anos. Está comigo desde os sete anos, diagnosticado pela escola como TDAH. Acho que trabalhei muito mal. Chegou mergulhado na posição de objeto, indiferenciado no campo do Outro, mas ele hoje entende muito bem o que seja responsabilidade subjetiva. Eu é que não sei mais se ele está preparado para viver num mundo onde o sujeito está cada vez mais dissolvido no coletivo.

Será que estamos preparados para atualizar nossos paradigmas à luz da normatividade tribalista que se anuncia no futuro próximo? Nós, psicanalistas, costumamos denunciar os efeitos do discurso da ciência sobre os corpos. Discursos que nos impõem, cada vez mais dietas, exerćcios, controles médicos rigorosos. Ainda que a lista de alimentos prescritos e alimentos proibidos seja muitas vezes contraditória, os preceitos para uma boa alimentação são cada vez mais estritos. Os pais, entretanto, não conseguem transmitir aos seus filhos estes preceitos saudáveis. 
O caso de Júlia, 12 anos, é muito mais revelador da subjetividade que se anuncia. Ela chega à entrevista com sono e de má vontade. Acha que está cansada e com fome. Embora estude em horário integral, não come na hora do almoço. Não gosta da comida. A carne é dura, o arroz é seco, não gosta de legumes e não come salada. Eu pergunto, com aquela proverbial "cara de tacho furado em baixo":

- "E pode não comer? Quem te autoriza a não almoçar?".

Ela responde sem nenhuma sombra de dúvida:

- "Depois da quinta série, o aluno tem o direito de não entrar no refeitório e não é obrigado a almoçar se não quiser".

Eu insisto mais um pouquinho.

- "Não é preciso se alimentar corretamente para crescer com saúde?".

Ela diz:

- "Eu não ligo pra isso".

Bom, geralmente é a mãe da criança que se preocupa com isso. Pensei na velha máxima: "água mole em pedra dura, tanto bate até que fura".

- "Minha mãe também não liga. Diz que está de saco cheio e que já deixou esse assunto pra lá".

- "Só você não come na escola?".

- "Ah, não! Tem um monte igual a mim".

Alguém se lembra daquela musiquinha: "Já é hora de dormir, não espere mamãe mandar...". Bons tempos! Muitos pais ignoram solenemente que a condição para estar acordado na sala de aula, é uma boa noite de sono. Nada mais distante do cotidiano de um grande numero de famílias do que a ideia deque a criança não é um adulto e que precisa da rotina para funcionar.

Todo mundo sabe que a prática do bullying tornou-se uma epidemia. É o paradoxo da escola inclusiva. $\mathrm{O}$ combate à segregação de portadores de deficiências físicas ou mentais convive com o crescimento da intolerância e da violência entre estudantes do ensino fundamental e médio. Observei que não são as crianças que desviam do padrão ideal de beleza, recursos financeiros e inteligência as mais assediadas moralmente pela prática do bullying. São justamente as crianças e adolescentes mais identificados com pais atenciosos, presentes, participantes e preocupados em transmitir os valores da diferença geracional e sexual. Enfim, os filhos de pais mais tradicionais são as vítimas preferenciais do bullying. Estas crianças não participam do pacto entre iguais, do mundo estritamente tribal, onde a juventude precocemente emancipada faz a regra. São percebidos como agentes infiltrados, representantes perigosos da autoridade dos adultos. São suspeitos. Podem trair os combinados, divergir dos comportamentos estabelecidos tribalmente em nome dessa coisa ultrapassada e anacrônica chamada consciência individual...

E, finalmente não posso deixar de lado uma importante retificação. Quem culpa a má qualidade da educação pública pela desigualdade social não quer saber nada sobre a incrível desigualdade intelectual entre os seres humanos. Quem disse que todo mundo nasce livre e igual? 
Os problemas fonológicos, os desvios do padrão de desenvolvimento cognitivo e o elevado percentual de crianças nas boas escolas particulares que - por mais que se matem de estudar - não conseguem acompanhar o currículo escolar, são o nosso dia a dia. São crianças e adolescentes sob constante supervisão dos pais e de professores particulares. Desmentem a tese amplamente aceita de que é a falta de acompanhamento escolar que leva ao fracasso. Embora não exista um currículo escolar padrão em nosso país, os currículos escolares adotados exigem habilidades cognitivas bastante elevadas. É urgente desencorajar os professores de estigmatizar estas crianças e adolescentes com o rótulo de preguiçosos, maus alunos que não estudam o suficiente.

Ana Luíza, 13 anos me disse:

- "Não é justo, eu preciso estudar quatro vezes mais do que os bons alunos. E nunca alcanço as mesmas notas".

Faço o mea culpa. Já acreditei que o fracasso escolar fosse somente a consequência da má qualidade da educação pública, da falta de acompanhamento escolar por parte dos pais ou de deficiências neuropsicológicas das crianças. Hoje eu verifico que as melhores escolas não estão à altura de proporcionar uma educação adequada às enormes diferenças entre os indivíduos. É um paradoxo impressionante. A escola contemporânea se pretende inclusiva. Crianças e adolescentes portadores de autismo, psicose infantil, surdez, atrasos graves no desenvolvimento cognitivo desafiam a capacidade dos professores de atender às suas necessidades especiais. Em contrapartida, os pequenos desvios do padrão continuam a representar um obstáculo intransponível, levando meninos e meninas como Ana Luiza ao desespero ante às exigências do aprendizado.

Para concluir, o projeto de uma sociedade igualitária, apoiado na universalização do acesso a educação, vacila. Qual é o real em jogo? Como analista, penso que a ideologia igualitária é um grande equívoco. A educação não leva à sua realização, ao contrário, acentua as diferenças, pois aparelha os mais aptos a trunfar. Vivemos num impasse aparentemente sem solução. Apostar na meritocracia e acentuar as diferenças ou fomentar a igualdade de todos com todos e o nivelamento por baixo?

\section{Notas}

${ }^{1}$ Artigo elaborado com base na Conferência de abertura ao IV Simpósio do ISEPOL em 2014.

2 Referente à assembleia de membros da École de la CauseFreudienne, em outubro de 2012.

\section{Referências bibliográficas}

Brousse, M.-H. (2009, set.). A psicose ordinária à luz da teoria lacaniana do discurso. Latusa digital, 6(38). Recuperado de http://www.latusa.com.br/pdf latusa digital 38 a1.pdf.

Coelho dos Santos, T. (2001). Quem precisa de análise hoje? - O discurso analítico: novos sintomas e novos laços sociais. Rio de Janeiro: Bertrand Brasil.

Coelho dos Santos, T. (2010). Ditadura da homogeneidade ou direito ao gozo autista do sinthoma? aSEPHallus - Revista de Orientação Lacaniana, 5(10). Recuperado de http://www.isepol.com/asephallus/numero 10/atualidades.html. 
Coelho dos Santos, T. (2012). O lugar certo onde colocar o desejo do analista na era dos direitos. aSEPHallus - Revista de Orientação Lacaniana, 714$)$. Recuperado de http://www.isepol.com/asephallus/numero 14/artigo 01.html.

Coelho dos Santos, T. (2013). A psicanálise é uma ciência e o discurso analítico é uma práxis? Revista Ágora, 16(2), 299-312. Recuperado de http://www.scielo.br/pdf/agora/v16n2/v16n2a08.pdf.

Coelho dos Santos, T. (2014a). Responsabilidade coletiva ou responsabilidade subjetiva: a saúde é um direito ou um dever? In BARROS R. M. M. \& ANCIÃES, V. (Orgs.). Psicanálise e saúde: entre o sujeito e o Estado. Rio de Janeiro: Cia de Freud. No prelo.

Coelho dos Santos, T. (2014b). Do supereu sujeitado à lei simbólica à normatividade supersocial dos corpos falantes. In Coelho dos Santos, T. et al. (Orgs.). Os corpos falantes e a normatividade do supersocial (pp. 27-62). Rio de Janeiro: Cia de Freud.

Ewald, F. (1993). Foucault, a norma e o direito. Lisboa: Vega.

Fonseca, M. S. (2013). A época da norma. Revista Cult, (134). Recuperado de http://revistacult.uol.com.br/home/2010/03/a-epoca-da-norma/.

Freud, S. (1974). Sobre o narcisismo: uma introdução. Edição standard brasileira das obras psicológicas completas de Sigmund Freud (Vol. 14, pp. 89-119). Rio de Janeiro: Imago (Trabalho original publicado em 1914).

Freud, S (1974). Os instintos e suas vicissitudes. Edição standard brasileira das obras psicológicas completas de Sigmund Freud (Vol. 14, pp. 137-162). Rio de Janeiro: Imago (Trabalho original publicado em 1915).

Freud, S (1976). Conferência XXXIV: explicações, aplicações, orientações. Edição standard brasileira das obras psicológicas completas de Sigmund Freud (Vol. 22, pp. 167-191). Rio de Janeiro: Imago (Trabalho original publicado em 1933).

Freud, S (1975). Análise terminável e interminável. Edição standard brasileira das obras psicológicas completas de Sigmund Freud (Vol. 23, pp. 247-287). Rio de Janeiro: Imago (Trabalho original publicado em 1937).

Lacan, J. (2013). Le seminaire, livre VI: le désir et son interprétation. Paris: La Martinière (Trabalho original publicado em 1958-1959).

Lacan, J. (1973-1974). Le seminaire, livre XIX: les nos dupes errent. Seminário Inédito.

Laurent, E. \& Miller, J.-A. (1997, mai.). Les pathologies contemporaines de I'identification: les pensionnats. Letterina, (16), 5-23.

Miller, J.-A. (2003). La experiencia de lo real en la cura psicoanalítica. Buenos Aires: Paidós (Trabalho original publicado em 1998-1999).

Miller, J.-A. (2009). Perspectivas do Seminário 23 de Lacan. O Sinthoma. Rio de Janeiro: Zahar (Trabalho original publicado em 2006-2007).

Miller, J.-A. (2011). Perspectivas dos Escritos e dos Outros escritos de Lacan, entre desejo e gozo. Rio de Janeiro: Zahar (Trabalho original publicado em 2008-2009). 
Miller, J.-A. (2012, mai-out.). Quando os desejos se tornam direitos. aSEPHallus - Revista de

$$
\text { Orientação Lacaniana, } \pi 14) \text { Recuperado de }
$$

http://www.isepol.com/asephallus/numero 14/atualidades 01.html.

Miller, J.-A. (2014). L'inconscientet le corps parlant. Recuperado de

http://wapol.org/fr/articulos/Template.asp?intTipoPagina=4\&intPublicacion=13\&intEdicion=9\&

intIdiomaPublicacion $=5$ \&intArticulo $=2742$ \&intIdiomaArticulo $=5$.

Miller, J.-A. (2014). O real no século XXI. Apresentação do tema do IX Congresso da AMP.

Recuperado de

http://wapol.org/pt/articulos/Template.asp?intTipoPagina=4\&intPublicacion=38\&intEdicion

$=$ 13\&intIdiomaPublicacion=9\&intArticulo=2493\&intIdiomaArticulo $=9$

Quetelet, A. (1991). Sur l'homme et le développement de ses facultes. Paris: Arthème-Fayard

(Trabalho original publicado em 1835).

Citacão/Citation: Coelho dos Santos, T. (nov. 2013 a abr. 2014). Ideologia, você quer uma pra viver? Revista aSEPHallus de Orientação Lacaniana, $9(17)$, 7-18. Disponível em www.isepol.com/asephallus. doi: 10.17852/1809-709x.2019v9n17p07-18.

Editor do artigo: Tania Coelho dos Santos.

Recebido/Received: 23/10/2013 / 10/23/2013.

Aceito/Accepted: 28/12/2013 / 12/28/2013.

Copyright: (c) 2013 Associação Núcleo Sephora de Pesquisa sobre o moderno e o contemporâneo. Este é um artigo de livre acesso, que permite uso irrestrito, distribuição e reprodução em qualquer meio, desde que o autor e a fonte sejam citados/Thisisan open-accessarticle, which permites unrestricted use, distribution, andreproduction in anymedium, providedtheauthorandsource are credited. 